\title{
SLC14A1 (UT-B) gene rearrangement in urothelial carcinoma of the bladder: a case report
}

\author{
Zhongying Guo', Xiaobing Niu², Guangbo Fu², Baoxue Yang ${ }^{3}$, Guangping Chen ${ }^{4^{*}}$ (D) and Su'an Sun ${ }^{*}$
}

\begin{abstract}
Background: Bladder cancer (BC) is a common and deadly disease. Over the past decade, a number of genetic alterations have been reported in BC. Bladder urothelium expresses abundant urea transporter UT-B encoded by Slc14a1 gene at 18q12.3 locus, which plays an important role in preventing high concentrated urea-caused cell injury. Early genome-wide association studies (GWAS) showed that UT-B gene mutations are genetically linked to the urothelial bladder carcinoma (UBC). In this study, we examined whether SIc14a1 gene has been changed in UBC, which has never been reported.
\end{abstract}

Case presentation: A 59-year-old male was admitted to a hospital with the complaint of gross hematuria for 6 days. Ultrasonography revealed a size of $2.8 \times 1.7 \mathrm{~cm}$ mass lesion located on the rear wall and dome of the bladder. In cystoscopic examination, papillary tumoral lesions $3.0-\mathrm{cm}$ in total diameter were seen on the left wall of the bladder and $2 \mathrm{~cm}$ to the left ureteric orifice. Transurethral resection of bladder tumor (TURBT) was performed. Histology showed high-grade non-muscle invasive UBC. Immunostaining was negative for Syn, CK7, CK20, Villin, and positive for HER2, BRCA1, GATA3. Using a fluorescence in situ hybridization (FISH), Slc14a1 gene rearrangement was identified by a pair of break-apart DNA probes.

Conclusions: We for the first time report a patient diagnosed with urothelial carcinoma accompanied with split Slc14a1 gene abnormality, a crucial gene in bladder.

Keywords: Bladder, Urothelial cancer, Fluorescence in situ hybridization, Gene rearrangement

\section{Introduction}

Urothelial bladder carcinoma (UBC) is the sixth most common cancer and occurs more often in men than in women. In 2004, the World Health Organization divided bladder tumors into muscle-invasive urothelial carcinoma and nonmuscle invasive urothelial neoplasia [1]. More than $70 \%$ of UBC patients are non-muscle invasive (superficial) UBC at initial diagnosis, whereas $30 \%$ are in muscle-invasive stage

\footnotetext{
*Correspondence: gchen3@emory.edu; hayyssa@163.com

${ }^{4}$ Department of Physiology, Emory University School of Medicine, Atlanta, GA 30322, USA

'Department of Pathology, Huai'an First People's Hospital, Nanjing Medical University, Huai'an 223300, China

Full list of author information is available at the end of the article
}

[1]. An important clinical feature of UBC is an unusually high propensity for recurring than in any other solid cancer. More than $70 \%$ of patients with UBC will have a recurrence during the first 2 years after diagnosis $[2,3]$. The recurrences are often accompanied by grade and/or stage progression with a very poor prognosis $[4,5]$.

In human, the urinary bladder is a special organ that is in constant contact with a high concentration of urea, 20-100 times higher than in blood. Urea is the major end-product of nitrogen metabolism and is excreted by the kidneys. Urea is a small molecule $(\sim 60 \mathrm{Da})$ and water solubility, however urea permeability across lipid bilayers is very low. Movement of urea across the cell membrane is mediated by urea transporter (UT) 
proteins [6-9]. In mammals, there are two subfamilies of UT, UT-A and UT-B, encoded by the Slc14a2 and Slc14a1 genes, respectively. UT-A urea transporters are mainly expressed in renal medulla and contribute to the kidney's ability to concentrate urine. UT-B has broadly tissue expression including bladder. Bladder urothelium only expresses UT-B [10-12]. This was confirmed by an RNA-sequencing analysis showing high expression of Slc14a1 (UT-B) and the absence of Slc14a2 (UT-A) in bladder tissues [13].

Evidences have shown that an excess of intracellular urea accumulation damages cells and cell functions (DNA damage, abnormal cell phenotype transformation, genetic pathway activation, etc.) $[11,14-16]$. Since the bladder stores urine, its urothelium is inevitably and constantly exposed to a higher concentration of urea than any other tissues. Therefore, the urothelial UT-B stands in a key position to prevent urea-induced insults by lowering intracellular urea levels. To support it, bladder urothelium expresses the most abundant urea transporter UT-B in vivo [10]. Dysfunction of UT-B will cause intracellular urea accumulation and profoundly affect cells. The impaired urothelial cells are then vulnerable to be attacked by urea and/or by carcinogen in urine, a potential important mechanism of tumorigenesis in UBC [17].

A previously study from our group revealed absence or a lower level of UT-B expression in UBC both at mRNA and protein levels. In some patients, a mutant UT-B with a 24-nt in-frame deletion (del24) in exon 4 was identified [17]. Since UT-B was undetectable in some UBC patients [17], we then asked whether this could be due to the UT-B (Slc14a1) gene rearrangement. We designed a pair of Slc14a1 gene break-apart DNA probes and performed fluorescence in situ hybridization (FISH). We found UT-B gene rearrangement occurred in one UBC patient from 14 cases. This is the first report of genomic abnormalities of split SLC14A1 gene identified in UBC.

\section{Case presentation}

A 59-year-old male was admitted to a hospital with the complaint of gross hematuria for 6 days. There was no abdominal or flank pain and other abnormal finding. No lymphadenopathy was identified. No abnormal laboratory findings were noted. The patient did not have family history of UBC. Ultrasonography revealed a size of $2.8 \times 1.7 \mathrm{~cm}$ mass lesion located on the rear wall and dome of the bladder. Bladder tumor was diagnosed. In cystoscopic examination, papillary tumoral lesions $3.0-\mathrm{cm}$ in total diameter were seen on the left wall of the bladder and $2 \mathrm{~cm}$ to the left ureteric orifice. Transurethral resection of bladder tumor (TURBT) was performed.
This study was conducted under the approval by the Clinical Research Ethics Committee of Huai'an Hospital, Nanjing Medical University. A signed informed consent was obtained from the patient for the use of tissue samples for this study.

\section{Pathologic findings}

The resected tissues were sent to the pathologic lab and fixed in $10 \%$ formalin. Paraffin tissue blocks were made as standard technique, and $3 \mu \mathrm{m}$ sections were prepared for pathological diagnosis, immunohistochemistry (IHC), and FISH test. Hematoxylin and eosin (HE) stained slides were reviewed independently by two senior pathologists. Pathological examination showed highgrade non-muscle invasive papillary urothelial carcinoma (Fig. 1).

\section{Immunohistochemical findings}

Immunohistochemistry analysis showed HER2 (3+), Syn $(-)$, BRCA1 $(2+)$, GATA3 (3+), Ki-67 (30\%+), CK7 (-), CK20 (-), Villin (-), p53 ( \pm ).

\section{Molecular findings}

FISH was performed using Slc14a1 break-apart rearrangement dual color probe in this experiment. The probe consists of two combinations, a $\sim 200 \mathrm{~kb}$ of DNA (RP11-1114E12) at the centromeric side of Slc14a1 gene being labelled by the tetramethyl rhodamine with a red fluorescence signal, $\mathrm{a} \sim 190 \mathrm{~kb}$ of DNA (RP11-366 J11) located in the telomeric side being marked by green fluorescence (Fig. 2a). RP11 bacterial artificial chromosome (BAC) clones with human genomic DNA were purchased from UCSF Benioff Children's Hospital Oakland. Plasmid DNAs were prepared by NucleoBond Xtra BAC large construct kit (Takara, 740,436.25). DNA

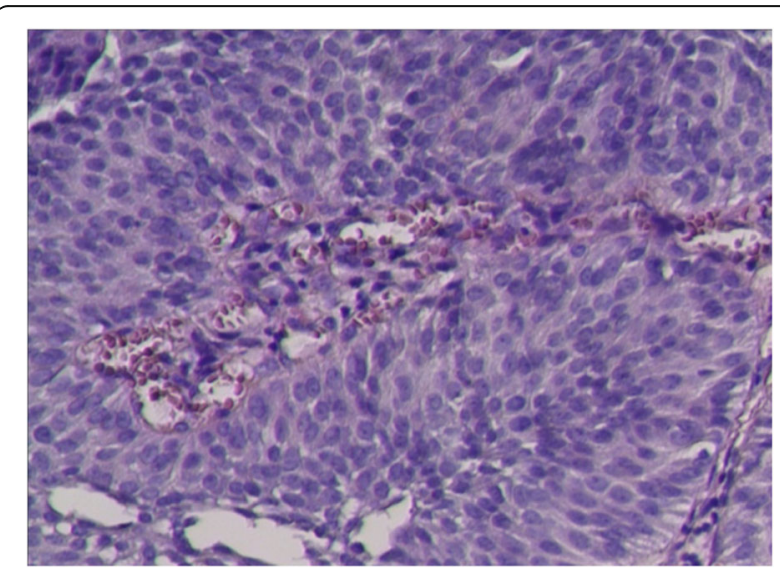

Fig. 1 Pathological examination. A 59-year-old male complaint of gross hematuria for 6 days. Transurethral resection of bladder tumor (TURBT) was performed. Histology shows typical morphology of bladder urothelial cancer 
A
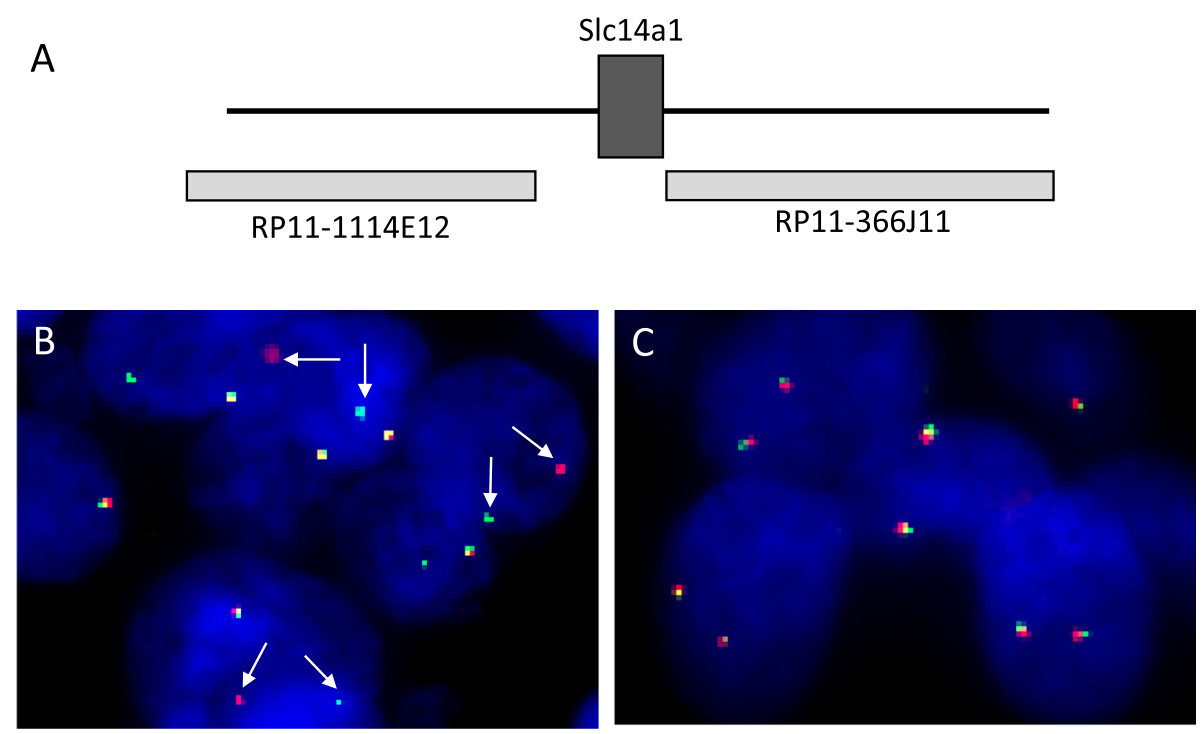

Fig. 2 FISH analysis using "break-apart" SIc14a1 gene probes. a. Illustration of FISH probe design and probe location. b. UT-B gene split was identified showing separated red dots and green dots (arrows) in cancer cells. c. Control. A representative image of UBC cell without UT-B gene split from a different patient. Normal signals are two close red and green colors with partial overlapped yellow color

probes were fluorescent labelled using Nick translation DNA labeling system (Enzo-GEN111).

Three micrometer thick sections were de-paraffinized in xylene, dehydrated with ethanol, pre-treated in $90^{\circ} \mathrm{C}$ water for $30 \mathrm{~min}$, and then incubated with $1 \mathrm{mg} / \mathrm{ml}$ pep$\sin$ (Amresco) solution at $42^{\circ} \mathrm{C}$ for $15 \mathrm{~min}$. The breakapart Slc14a1 probe set including human Cot-1 DNA was applied to individual slides. Human Cot-1 DNA (Fisher, 15,279,011) was used to block non-specific sequences. After denatured at $86^{\circ} \mathrm{C}$ for $8 \mathrm{~min}$, the sections were incubated for $16 \mathrm{~h}$ at $38^{\circ} \mathrm{C}$ using Automated ThermoBrite FISH System (Leica Biosystems). Posthybridization washes were carried out with $2 \times \mathrm{SSC}$ for $3 \mathrm{~min}$ at room temperature followed by $2 \mathrm{X}$ SSC/0.1\% $\mathrm{NP}-40$ solution at $72{ }^{\circ} \mathrm{C}$ for $5 \mathrm{~min}$ and gradient dehydration in 70, 85 and 100\% ethanol. The sections were airdried, protected from light and mounted with Fluorescence Mounting Medium containing DAPI (Sigma F6057). The fluorescence was viewed under Olympus FV1000 Upright fluorescence microscope. The fluorescence signals were evaluated in 50 nuclei for each tumor core under a 100x immersion objective. According to Noda's diagnostic criteria [18] for MAML2 gene split in mucoepidermoid carcinoma, we considered the positive Slc14a1 rearrangement if $>10$ split signals of 50 nuclei were found.

The hybridization signals of Slc14a1 break-apart probe showed two very close red and green colors with partially overlapped yellow colors indicating normal unbroken Slc14a1 gene. Figure 2c showed a representative image of FISH results without UT-B gene split. When the Slc14a1 gene break apart occurred, the signals are changed from merged yellow to single red and green as positive of UT-B gene split. From total 14 cases of UBC patients, we found that one patient (case report in this study) demonstrated break-apart signal patterns of Slc14a1 gene (Fig. 2b).

\section{Discussion}

UBC is a complex and heterogeneous disease caused by both genetic and environmental factors. The "urogenous contact hypothesis" proposed by Braver [19] in 1987 is still prevalent in the etiology of UBC. However, one important factor that we may have ignored in bladder carcinogenesis is urea. The urea concentration in urine is 20-100 times higher than that in blood in humans $[20,21]$. Interestingly, the risk of UBC for people with spinal cord injuries is 16-28 times higher than that for the general population [22, 23], underscoring the important role of endogenous factors, including urea, in the bladder tumorigenesis.

Considering that the bladder urothelium is bathed in fluid with a high urea concentration and the toxicity of intracellular urea accumulation, the urea transporter is extremely important for bladder urothelium by lowering intracellular urea levels. Experimental studies have shown that deletion of UT-B gene causes urea accumulation in urothelium $\sim 9$ times higher in UT-B knockout mice [11, 24]. This is accompanied by increased cell DNA damage, apoptosis and diminished arginine metabolism [11, 24]. Therefore, loss of UT-B protection will render urothelial cells at risk under constantly high urea 
insult, then either directly activates genetic pathways that induce UBC or synergistically increases UBC risk by facilitating other carcinogen-induced mechanisms of UBC. In 2011, genome-wide association studies (GWAS) from two independent groups $[25,26]$ reported a number of gene variants of nucleotide polymorphisms within SLC14A1 (UT-B gene) on chromosome 18q12.3, are associated with risk of developing UBC in humans, suggesting the possible tumor suppressor role of UT-B in UBC.

Genomic alterations are quite common in UBC [1]. Previous gene analysis revealed three types of UT-B gene abnormality in UBC $[17,1)$ no or under-detectable mRNA expression; (2) truncated short form of UT-B; (3) UT-B with a 24-nt in-frame deletion (del24) in exon 4 (UT-B $\Delta 24)$. In this study, we attempted to figure out whether in some UBC patients the absence of UT-B mRNA expression [17] measured by RT-PCR is due to Slc14a1 gene rearrangement. Using a set of Slc14a1 break apart DNA probes, we performed FISH test by using FFPE tissue sections from 14 UBC patients. A patient of a 59-year-old male diagnosed with superficial, non-muscle invasive UBC clearly showed split Slc14a1 gene signals (Fig. 2b). Gene split has been demonstrated in several cancers [27-29]. This is the first report demonstrating a case of UBC with Slc14a1 gene rearrangement.

\section{Conclusions}

Although the Slc14a1 as a new urinary UBC susceptibility gene was appreciated $[25,26]$, the role and the molecular mechanism of the UT-B in bladder oncogenesis have not been well explored to date. The discovery of Slc14a1 gene rearrangement in this study is interesting and may have clinical significance. Further investigation is needed to substantiate this finding and determine whether the Slc14a1 gene rearrangement is associated with tumor cell invasion, metastatic spread, aggressiveness, tumor progression, recurrence and clinical outcomes.

\section{Abbreviations}

BC: Bladder cancer; UBC: Urothelial bladder carcinoma; UT: Urea transporter; GWAS: Genome-wide association studies; FISH: Fluorescence in situ hybridization; IHC: Immunohistochemistry

\section{Acknowledgements}

Not Applicable.

\section{Authors' contributions}

ZG, XN carried out the experiments and data collection; GF, BY, GC, SS analyzed and interpreted data; GC, SS concepted and designed the experiments; GC, SS wrote the manuscript. All authors have read and approved the manuscript.

\section{Funding}

This work was supported by grants from Huai'an Promotion Project for science and technology international cooperation (HAC201708) to S.S.
Natural Science Foundation of Huai'an (HAB201801) to X. L. National Natural Science Foundation of China 81620108029 to B.Y. Emory URC grant 13492009 to G.C.

The funds provided were used to finance laboratory expenses (materials and reagents). The funder had no role in the design of the study, the collection of data, the analysis and interpretation of results, or in writing the manuscript.

\section{Availability of data and materials}

The datasets used and/or analyzed during the current study available from the corresponding author on reasonable request.

\section{Ethics approval and consent to participate}

The Clinical Research Ethics Committee of Huai'an Hospital, Nanjing Medical University approved this study (No. hasyy20130729003). An approved written informed consent was obtained from all participants.

\section{Consent for publication}

Written consent was obtained from the patient to publish this case report.

\section{Competing interests}

The authors declare that they have no competing interests.

\section{Author details}

'Department of Pathology, Huai'an First People's Hospital, Nanjing Medical University, Huai'an 223300, China. ${ }^{2}$ Department of Urology, Huai'an First People's Hospital, Nanjing Medical University, Huai'an 223300, China. ${ }^{3}$ Department of Pharmacology, School of Basic Medical Sciences, Peking University, Beijing 100191, China. ${ }^{4}$ Department of Physiology, Emory University School of Medicine, Atlanta, GA 30322, USA.

Received: 13 April 2020 Accepted: 14 July 2020

Published online: 23 July 2020

\section{References}

1. Ye F, Wang L, Castillo-Martin M, McBride R, Galsky MD, Zhu J, Boffetta P, Zhang DY, Cordon-Cardo C. Biomarkers for bladder cancer management: present and future. Am J Clin Exp Urol. 2014;2(1):1-14.

2. Siegel RL, Miller KD, Jemal A. Cancer statistics, 2015. CA Cancer J Clin. 2015; 65(1):5-29.

3. Bellmunt J, Nadal R. Urothelial cancer in 2017: changes in expectations for metastatic urothelial carcinoma. Nat Rev Clin Oncol. 2018;15(2):73-4.

4. Al-Sukhun S, Hussain M. Current understanding of the biology of advanced bladder cancer. Cancer. 2003;97(8 Suppl):2064-75.

5. Netto GJ, Tafe LJ. Emerging bladder Cancer biomarkers and targets of therapy. Urol Clin N Am. 2016;43(1):63-76.

6. Sands JM. Mammalian urea transporters. Annu Rev Physiol. 2003;65:543-66.

7. Sands JM. Critical role of urea in the urine-concentrating mechanism. J Am Soc Nephrol. 2007;18(3):670-1.

8. Li X, Chen G, Yang B. Urea transporter physiology studied in knockout mice. Front Physiol. 2012;3:217

9. Klein JD, Blount MA, Sands JM. Urea transport in the kidney. Compr Physiol. 2011;1(2):699-729.

10. Yang B, Bankir L, Gillespie A, Epstein CJ, Verkman AS. Urea-selective concentrating defect in transgenic mice lacking urea transporter UT-B. J Biol Chem. 2002;277(12):10633-7.

11. Dong Z, Ran J, Zhou H, Chen J, Lei T, Wang W, Sun Y, Lin G, Bankir L, Yang B. Urea transporter UT-B deletion induces DNA damage and apoptosis in mouse bladder urothelium. PLoS One. 2013;8(10):e76952.

12. Walpole C, Farrell A, McGrane A, Stewart GS. Expression and localization of a UT-B urea transporter in the human bladder. Am J Physiol Ren Physiol. 2014;307(9):F1088-94.

13. Koutros S, Baris D, Fischer A, Tang W, Garcia-Closas M, Karagas MR, Schwenn M, Johnson A, Figueroa J, Waddell R, et al. Differential urinary specific gravity as a molecular phenotype of the bladder cancer genetic association in the urea transporter gene, SLC14A1. Int J Cancer. 2013;133(12):3008-13.

14. Zou Q, Habermann-Rottinghaus SM, Murphy KP. Urea effects on protein stability: hydrogen bonding and the hydrophobic effect. Proteins. 1998; 31(2):107-15. 
15. Michea L, Ferguson DR, Peters EM, Andrews PM, Kirby MR, Burg MB. Cell cycle delay and apoptosis are induced by high salt and urea in renal medullary cells. Am J Physiol Ren Physiol. 2000;278(2):F209-18.

16. Zhang Z, Dmitrieva NI, Park JH, Levine RL, Burg MB. High urea and NaCl carbonylate proteins in renal cells in culture and in vivo, and high urea causes 8-oxoguanine lesions in their DNA. Proc Natl Acad Sci U S A. 2004; 101(25):9491-6.

17. Hou R, Alemozaffar M, Yang B, Sands JM, Kong X, Chen G. Identification of a novel UT-B urea transporter in human Urothelial Cancer. Front Physiol. 2017;8:245.

18. Noda H, Okumura Y, Nakayama T, Miyabe S, Fujiyoshi Y, Hattori H, Shimozato K, Inagaki H. Clinicopathological significance of MAML2 gene split in mucoepidermoid carcinoma. Cancer Sci. 2013;104(1):85-92.

19. Braver DJ, Modan M, Chetrit A, Lusky A, Braf Z. Drinking, micturition habits, and urine concentration as potential risk factors in urinary bladder cancer. J Natl Cancer Inst. 1987;78(3):437-40.

20. Yang B, Bankir L. Urea and urine concentrating ability: new insights from studies in mice. Am J Physiol Ren Physiol. 2005;288(5):F881-96.

21. Spector DA, Yang Q, Wade JB. High urea and creatinine concentrations and urea transporter B in mammalian urinary tract tissues. Am J Physiol Ren Physiol. 2007;292(1):F467-74.

22. Hess MJ, Zhan EH, Foo DK, Yalla SV. Bladder cancer in patients with spinal cord injury. J Spinal Cord Med. 2003;26(4):335-8.

23. Bothig R, Kurze I, Fiebag K, Kaufmann A, Schops W, Kadhum T, Zellner M, Golka K. Clinical characteristics of bladder cancer in patients with spinal cord injury: the experience from a single Centre. Int Urol Nephrol. 2017; 49(6):983-94.

24. Li X, Ran J, Zhou H, Lei T, Zhou L, Han J, Yang B. Mice lacking urea transporter UT-B display depression-like behavior. J Mol Neurosci. 2012; 46(2):362-72.

25. Garcia-Closas M, Ye Y, Rothman N, Figueroa JD, Malats N, Dinney CP, Chatterjee N, Prokunina-Olsson L, Wang Z, Lin J, et al. A genome-wide association study of bladder cancer identifies a new susceptibility locus within SLC14A1, a urea transporter gene on chromosome 18q12.3. Hum Mol Genet. 2011;20(21):4282-9

26. Rafnar T, Vermeulen SH, Sulem P, Thorleifsson $G$, Aben KK, Witjes JA, Grotenhuis AJ, Verhaegh GW, Hulsbergen-van de Kaa CA, Besenbacher S, et al. European genome-wide association study identifies SLC14A1 as a new urinary bladder cancer susceptibility gene. Hum Mol Genet. 2011;20(21): 4268-81.

27. Soda M, Choi YL, Enomoto M, Takada S, Yamashita Y, Ishikawa S, Fujiwara S, Watanabe $\mathrm{H}$, Kurashina $\mathrm{K}$, Hatanaka $\mathrm{H}$, et al. Identification of the transforming EML4-ALK fusion gene in non-small-cell lung cancer. Nature. 2007:448(7153):561-6.

28. Savage KJ, Johnson NA, Ben-Neriah S, Connors JM, Sehn LH, Farinha P, Horsman DE, Gascoyne RD. MYC gene rearrangements are associated with a poor prognosis in diffuse large B-cell lymphoma patients treated with RCHOP chemotherapy. Blood. 2009:114(17):3533-7.

29. Rogers TM, Arnau GM, Ryland GL, Huang S, Lira ME, Emmanuel Y, Perez OD, Irwin D, Fellowes AP, Wong SQ, et al. Multiplexed transcriptome analysis to detect ALK, ROS1 and RET rearrangements in lung cancer. Sci Rep. 2017;7: 42259 .

\section{Publisher's Note}

Springer Nature remains neutral with regard to jurisdictional claims in published maps and institutional affiliations.

Ready to submit your research? Choose BMC and benefit from:

- fast, convenient online submission

- thorough peer review by experienced researchers in your field

- rapid publication on acceptance

- support for research data, including large and complex data types

- gold Open Access which fosters wider collaboration and increased citations

- maximum visibility for your research: over $100 \mathrm{M}$ website views per year

At BMC, research is always in progress.

Learn more biomedcentral.com/submissions 